\title{
Desenvolvimento e produtividade de quinoa semeada em diferentes datas no período safrinha ${ }^{1}$
}

\author{
Development and productivity of quinoa sown on different dates the during off- \\ season
}

\author{
Fernando Soares de Vasconcelos ${ }^{2}$, Edmar Soares de Vasconcelos ${ }^{3 *}$, Marcelo Gonçalves Balan ${ }^{4}$ e Lucas Silvério ${ }^{5}$
}

\begin{abstract}
RESUMO - Este trabalho foi realizado com o objetivo de avaliar o desenvolvimento e a produtividade de Quinoa variedade BRS-Piabiru semeada em diferentes datas dentro do período safrinha, em Campo Mourão, PR. Foram avaliadas seis datas de semeadura, a saber: 18/03/08, 02/04/08, 17/04/08, 02/05/08, 17/05/08 e 10/06/08. Os índices da cultura avaliados foram número de dias para a floração; número de dias para a maturação; altura das plantas na maturação e produtividade. $\mathrm{O}$ experimento foi realizado no delineamento experimental em blocos completos com os tratamentos ao acaso e em quatro repetições. Os resultados indicam que a data de semeadura teve influência no número de dias para a floração; número de dias para a maturação; altura das plantas na maturação e produtividade. A maior altura de plantas juntamente à maior produtividade de quinoa foram obtidas em 18 de março.
\end{abstract}

Palavras-chave: Quinoa. Cultivos agrícolas-rendimento. Semeadura.

\begin{abstract}
This work was carried out with the aim of evaluating the development and productivity of the BRSPiabiru variety of quinoa when sown on different dates during the off-season at Campo Mourao, PR. Six sowing dates were evaluated, namely: March 18, 2008; April 2, 2008; April 17, 2008; May 2, 2008; May 17, 2008; and June 10, 2008. The culture indices evaluated were the number of days to flowering, the number of days to maturity, plant height at maturity, and productivity. The experiment was conducted in a complete-block design with random treatments and four replications. The results indicate that the seeding date had an influence on the number of days to flowering, number of days to maturity, plant height at maturity, and productivity. The greatest plant height, together with the highest productivity for quinoa were obtained on March 18.
\end{abstract}

Key words: Quinoa. Yield crops. Production. Sowing.

\footnotetext{
*Autor correspondência

${ }^{1}$ Recebido para publicação em 16/09/2010; aprovado em 06/01/2012

Pesquisa financiada pela FUNADESP, corresponde ao trabalho de iniciação científica do primeiro autor

${ }^{2}$ Faculdade Integrado de Campo Mourão, Rodovia BR 158, KM 207, Campo Mourão-PR, Brasil, 87.300-970, fernando.vasconcelos@ grupointegrado.br ${ }^{3}$ Departamento de Agronomia da Unioeste/Universidade Estadual do Oeste do Paraná, Rua: Pernambuco 1777, Marechal Cândido Rondon-PR, Brasil, 85.960-000, vasconceloses@pop.com.br

${ }^{4}$ Departamento de Agronomia da UEM/Universidade Estadual de Maringá, Campus Universitário - Av.: Colombo 5790, Bloco J-45, 87.020-900, Maringá-PR, Brasil, mgbalan2@uem.br

${ }_{5}^{5}$ Departamento de Agronomia da Faculdade Integrado de Campo Mourão, Rodovia BR 158, KM 207, Campo Mourão-PR, Brasil, 87.300-970, marcelo. balan@grupointegrado.br, silverio@grupointegrado.br
} 


\section{INTRODUÇÃO}

A quinoa ou quínua (Chenopodium quinoa Willd.), da família Chenopodiaceae, apresenta grande importância granífera por sua qualidade proteíca, a qual apresenta valor biológico equivalente ao da caseína do leite (CARBONE-RISI, 1986). Pelo fato de a quinoa apresentar elevado equilíbrio de aminoácidos, reduzido nível de colesterol e ausência de glúten, ela tem sido qualificada como o melhor alimento de origem vegetal para o consumo humano. Sendo o vegetal de maior equilíbrio nutricional do planeta, muito superior aos alimentos de origem animal, como a carne, o leite, os ovos e o peixe (SPEHAR; SANTOS, 2003).

A qualidade nutricional da quinoa tem levado pesquisadores à realização de inúmeros estudos nas últimas décadas, principalmente quanto ao seu sistema de produção e sua adaptação às diferentes condições ambientais. Spehar e Sousa (1993) avaliando a adaptação de diferentes materiais genéticos de quinoa no Brasil proporcionaram o lançamento da BRS-Piabiru para cultivo nas condições brasileiras (SPEHAR; SANTOS, 2002). Sendo ainda realizado seleção de materiais genéticos diferentes da BRS-Piabiru e com possibilidades de serem lançadas como novas variedades (ROCHA, 2008). Outro trabalho avaliando o comportamento da quinoa, trata da avaliação dessa cultura na presença de resíduos químicos de herbicidas no solo (SANTOS et al., 2003), e ainda a reação da quinoa quando cultivada na presença de nematóides (INOMOTO et al., 2007).

A exploração agropecuária da cultura de quinoa é dificultada pela grande influência ambiental em seu rendimento,especialmenteanomaliasnegativasdeprecipitação e temperatura, ocasionando preocupação contínua e crescente em relação à sua produção (ROCHA, 2008). Neste sentido, linhas de pesquisa a serem desenvolvidas devem preocupar em adotar um conjunto de práticas necessárias para aumentar sua produção, facilitando o cultivo em larga escala.

A determinação da época de semeadura é uma prática bastante antiga, mas que sempre exige novos estudos, em virtude da contínua evolução das condições ambientais, genotípicas e tecnológicas. Um exemplo disso pode ser visualizado no trabalho com a mamona, em que foi verificado que a variação na época de plantio influenciou em diversas características do sistema produtivo dessa cultura (SOUZA et al., 2007; ZUCHI et al., 2010a; ZUCHI et al., 2010b). De maneira geral, a determinação da época de semeadura visa estabelecer um ajuste entre o período crítico da cultura para suas exigências bioclimáticas e o período de máxima disponibilidade climática da região na qual está instalada ou pretende-se instalar a cultura (QUEIROZ et al., 1998).

A quinoa é considerada uma espécie anual. Na região do cerrado brasileiro seu ciclo pode variar de 80 a 150 dias. Apresenta crescimento rápido após a semeadura, com altura das plantas podendo variar de 0,65 até $2,0 \mathrm{~m}$ dependendo do genótipo. A deposição de oxalato de cálcio nas folhas (característica da espécie) lhe possibilita reter umidade, característica desejável na tolerância à seca e a geadas. Seus frutos são do tipo aquênio, com formato achatado, pequenos e não possuem dormência (TAPIA, 1997).

Atualmente a quinoa tem sua semeadura dependente do cultivo de outras culturas de verão, tais como soja e milho, isso porque é uma cultura pouco difundida no Brasil, sendo uma cultura secundária dentro do processo produtivo. De maneira que, o uso de cultivares precoces de soja como cultivo principal viabiliza a produção de quinoa, em sucessão, como safrinha (SPEHAR; SANTOS, 2002) na região do Paraná.

Este trabalho foi realizado com o objetivo de avaliar o desenvolvimento e a produtividade de quinoa variedade BRS-Piabiru em diferentes datas de semeadura (18/03/08, 02/04/08, 17/04/08, 02/05/08, 17/05/08 e 01/06/08), dentro do período safrinha na região de Campo Mourão, PR.

\section{MATERIAL E MÉTODOS}

O experimento foi conduzido no campus da Faculdade Integrado de Campo Mourão, Paraná, Brasil, no ano de 2008. O clima da região é caracterizado como subtropical úmido mesotérmico com verões quentes e tendência de concentração de chuvas (temperatura média, superior a $22{ }^{\circ} \mathrm{C}$ ), invernos com geadas pouco frequentes (temperatura média, inferior a $18{ }^{\circ} \mathrm{C}$ ), sem estação seca definida. A precipitação média é de $1.617 \mathrm{~mm}$ anuais. A altitude média está em torno de 630 m em relação ao nível do mar. O solo é caracterizado como Latossolo Vermelho distroférrico.

$\mathrm{O}$ experimento foi implantado via sistema de semeadura direta em solo anteriormente cultivado com aveia, a qual foi dessecada para implantação do experimento. Foi realizada adubação de base com $250 \mathrm{~kg} \mathrm{ha}^{-1}$ do formulado 08-20-20 no momento da semeadura, sendo $\mathrm{o}$ adubo disposto $5 \mathrm{~cm}$ abaixo das sementes.

Foi utilizada a variedade BRS-Piabiru para análise da influência da data de semeadura nos seguintes índices fitotécnicos: número de dias para a floração; número de dias para a maturação; altura das plantas na maturação e produtividade. $\mathrm{O}$ experimento foi instalado levando em consideração as datas de semeadura, da seguinte forma: 18/03/08, 02/04/08, 17/04/08, 02/05/08, 17/05/08 e 01 ou $01 / 06 / 08$, sendo a colheita realizada quando as plantas da parcela útil estavam com $90 \%$ da inflorescência, em coloração característica de maturação da variedade.

No experimento utilizou-se delineamento experimental em blocos completos com os tratamentos ao acaso e em quatro repetições, totalizando 24 parcelas, que foram distanciadas em 1,0 metro entre elas, de maneira a 
evitar o sombreamento. Cada parcela medindo $2 \times 5 \mathrm{~m}\left(10 \mathrm{~m}^{2}\right)$ foi constituída de quatro linhas distanciadas $0,5 \mathrm{~m}$ entre si, com 5,0 m de comprimento. Aos 15 dias foi realizado o desbaste das plantas de cada linha, essa operação foi realizada visando deixar 10 plantas por metro linear. A produtividade da cultura foi determinada a partir da área útil das parcelas, correspondente às duas linhas centrais, com 4,0 m de comprimento, desprezando $0,5 \mathrm{~m}$ em cada extremidade da parcela.

A análise estatística consistiu na análise dos erros dos dados coletados, os quais foram submetidos ao teste de normalidade (teste de Lilliefors), verificando-se a necessidade ou não de transformação dos mesmos. Para comparação entre as médias obtidas para cada época de semeadura, utilizou-se o teste de Tukey a $5 \%$ de probabilidade $(\mathrm{p}<0,05)$. Depois de gerado o resultado da comparação de médias pelo teste de Tukey, foi obtido o Índice de Diferenciação de Fasoulas para cada média por meio da seguinte expressão: $\operatorname{ID}_{\mathrm{i}}=200 \mathrm{M} /[\mathrm{N}(\mathrm{N}-1)]$, para $\mathrm{i}=1,2, \ldots, \mathrm{N}$. Em que, $\mathrm{ID}_{\mathrm{i}}$ corresponde ao índice de diferenciação de Fasoulas para cada média i; No número de médias submetidas ao teste de médias; e, $\mathrm{M}$ o número de médias que o tratamento i superou, estatisticamente, pelo teste de médias de Tukey. As análises estatísticas foram processadas com o auxílio do aplicativo computacional "Genes" (CRUZ, 2006).

\section{RESULTADOS E DISCUSSÃO}

Os resultados obtidos indicam que houve resposta significativa da data de semeadura de quinoa sobre o número de dias para floração, número de dias para maturação, altura de plantas na maturação e produtividade (Tabela 1).

Os erros segundo o modelo, para os dados de produtividade apresentaram distribuição normal pelo teste de normalidade de Lilliefors, não sendo requerida a transformação dos dados para a realização da análise de variância, conforme recomendações de Couto et al. (2009).

Oefeito da data de semeadura nodesenvolvimento da quinoa está possivelmente relacionado ao fato dessa espécie ser classificada como planta de dias curtos, florescendo quando os dias diminuem seu comprimento (CARBONE-RISI, 1986; NELSON, 1968). Na Figura 1 esse comportamento fica evidenciado, uma vez que existe relação entre a data de semeadura e o número de dias para o florescimento da quinoa. Sendo o número máximo de dias para o florescimento alcançado quando a quinoa foi semeada na primeira quinzena de maio. Tanto a altura de plantas quanto o número de dias para maturação não tiveram relação linear definida para com a data de semeadura, existe apenas a influencia entre essas variáveis, evidenciada pela análise de variância.

O ciclo médio da cultivar BRS-Piabiru observado foi de 136 dias, valor dentro do determinado por Spehar e Santos (2003) para as condições do Brasil Central, definido entre 80 e 150 dias. A altura média das plantas verificada no período safrinha foi de 0,65 metros, valor esse que corresponde a cerca de 35\% do relatado por Spehar e Santos (2003) para condições de cultivos tardios (safrinha) no Brasil Central. De acordo com os mesmos, a quinoa pode chegar a 2,0 metros de altura nas condições de Brasil Central.

O coeficiente de variação da variável número de dias para floração e número de dias para maturação da quinoa foi inferior a $10 \%$. Segundo a classificação sugerida por Pimentel-Gomes (1985) esses coeficientes de variação são tidos como baixos. Enquanto para as variáveis altura de plantas na maturação e produtividade, os coeficientes de variação estiveram entre 10 e 20\%, sendo classificados como médios. Esse resultado dos coeficientes de variação mostra a confiabilidade dos dados, evidenciando a precisão do experimento.

Tabela 1 - Resumo da análise de variância dos dados de altura de plantas na maturação (APM) (cm), número de dias para floração (NDF), número de dias para maturação (NDM) e produtividade (kg ha-1) de Quinoa variedade BRS-Piabiru semeadas nos dias 18/03/08, 02/04/08, 17/04/08, 02/05/08, 17/05/08 e 01/06/08 em Campo Mourão, PR

\begin{tabular}{lcrrrr}
\hline \multirow{2}{*}{ Fontes de Variação } & \multirow{2}{*}{ GL } & \multicolumn{4}{c}{ Quadrados Médios } \\
\cline { 3 - 6 } & & APM & NDF & NDM & Produtividade \\
\hline Blocos & 3 & 0,003 & 1,042 & 0,264 & 5162,806 \\
Data de Semeadura & 5 & $0,039 * *$ & $188,742 * *$ & $502,242 * *$ & $1060736,417 * *$ \\
Resíduo & 15 & 0,005 & 2,475 & 3,464 & 8487,389 \\
Total & 23 & 0,012 & 42,781 & 111,476 & 236803,536 \\
Média & & 0,658 & 81,458 & 136,792 & 846,333 \\
CV. $(\%)$ & & 10,783 & 1,931 & 1,361 & 10,885 \\
\hline
\end{tabular}

** - Significativo a $1 \%$ pelo teste $\mathrm{F}$ 
Figura 1 - Comportamento do número de dias para floração de Quinoa (BRS-Piabiru) produzida com semeadura em diferentes datas, na Região de Campo Mourão, em Campo Mourão, PR. *-Significativo pelo teste t a $5 \%$

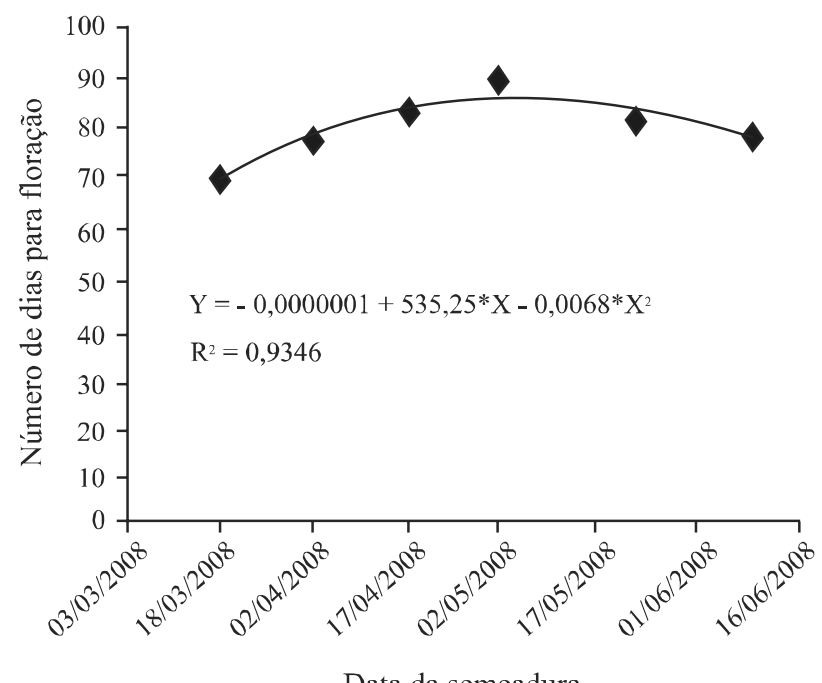

Data da semeadura

A semeadura de 18 de março gerou plantas de quinoa com menor número de dias para a floração, enquanto na semeadura de 05 de maio as plantas demandaram um maior período para a floração (Tabela 2). Na semeadura em 18 de abril as plantas de quinoa atingiram a maturação mais cedo, com 130 dias aproximadamente, enquanto que na semeadura em 23 de maio as plantas levaram 155 dias, aproximadamente, para maturação.

De maneira geral, dentro da mesma época de semeadura quanto maior o tempo de enchimento de grãos, maior será a produtividade da cultura (DAYNARD; TANNER; DUCCAN, 1971; OSÓRIO; WENDT, 1995;
YANG et al. 2008). Contudo, em datas de semeadura diferentes, a quinoa não teve sua produtividade dependente apenas do período de enchimento de grãos, uma vez que a semeadura realizada em 23/05/08 teve 70 dias para o enchimento de grãos e sua produtividade foi uma das menores não superando nenhuma outra pelo índice de Fasoulas. Ao passo que a semeadura em 18 de março com 64 dias de formação e enchimento de grãos foi a que gerou maior produtividade (Tabela 3). De maneira que outros fatores tiveram interferência nesse processo, podendo ser a temperatura, disponibilidade de água no solo, ou outro não controlado no experimento.

A semeadura da quinoa durante o mês de maio levou as plantas a exigirem maior número de dias para a maturação (Tabela 2).

As maiores alturas de plantas foram obtidas nas três semeaduras iniciais (18 de março, 02 e 18 de abril). Esse resultado é comprovado pelo índice de Fasoulas, em que as alturas de plantas dessas datas de semeadura superaram as alturas das plantas semeadas em datas sobrejacentes, as quais não foram maiores que nenhuma média, gerando índice de Fasoulas igual a zero (Tabela 3).

Os resultados para a altura de plantas evidenciam a relação entre temperatura no estádio vegetativo e o desenvolvimento das mesmas. De maneira que as datas de semeadura de abril e março, meses mais quentes, geraram plantas maiores que a das semeaduras de maio e junho (Tabela 3 ).

Os resultados de altura de plantas e produtividade de quinoa variedade BRS-Piabiru evidenciam que a melhor data de semeadura da quinoa dentro do período safrinha, nas condições analisadas, foi dia 18/03/08. Contudo, outros trabalhos de pesquisa devem ser realizados, nas condições Sul do Brasil, para se chegar

Tabela 2 - Valores médios do número de dias para floração e do número de dias para maturação da Quinoa variedade BRS-Piabiru semeada em diferentes datas em Campo Mourão, PR

\begin{tabular}{lllrrrrr}
\hline \multicolumn{1}{c}{ Data de Semeadura } & \multicolumn{2}{c}{ Número de Dias Para Floração } & \multicolumn{2}{c}{ Número de Dias Para Maturação } & NDFM $^{1}$ \\
\hline 18 de março de 2008 & 70,500 & $\mathrm{~d}^{3}$ & $0,00^{4}$ & 134,500 & $\mathrm{c}^{3}$ & $13,33^{4}$ & 64 \\
02 de abril de 2008 & 77,750 & $\mathrm{c}$ & 6,67 & 134,750 & $\mathrm{c}$ & 13,33 & 57 \\
18 de abril de 2008 & 84,000 & $\mathrm{~b}$ & 13,33 & 129,250 & $\mathrm{~d}$ & 6,67 & 45 \\
05 de maio de 2008 & 90,750 & $\mathrm{a}$ & 33,33 & 144,250 & $\mathrm{~b}$ & 26,67 & 54 \\
23 de maio de 2008 & 84,500 & $\mathrm{~b}$ & 13,33 & 154,750 & $\mathrm{a}$ & 33,33 & 70 \\
10 de junho de 2008 & 81,250 & $\mathrm{bc}$ & 6,67 & 123,250 & $\mathrm{e}$ & 0,00 & 42 \\
DMS $^{2}$ & 3,618 & & & 4,281 & & & - \\
\hline
\end{tabular}

1- Número de dias entre a floração e a maturação; ${ }^{2}$ - Diferença mínima significativa para comparação de médias, pelo teste de Tukey a 5\% de erro tipo I,

3. Esquema de comparação de médias pelo teste de Tukey, médias seguidas de mesma letra na coluna não diferem entre si pelo teste Tukey ao nível de $5 \%$ de significância. ${ }^{4}$ - Resultados do teste de Fasoulas na comparação de médias, pelo teste de Tukey a 5\%, entre as diferentes datas de semeadura 
Tabela 3 - Valores médios da altura de plantas na maturação $(\mathrm{m})$ e produtividade (kg ha $\left.{ }^{-1}\right)$ de Quinoa (BRS-Piabiru) quando semeada em diferentes datas dentro do período safrinha, em Campo Mourão, PR

\begin{tabular}{lcccccc}
\hline \multicolumn{1}{c}{ Datas de Semeadura } & \multicolumn{2}{c}{ Altura de Plantas na Maturação $(\mathrm{m})$} & \multicolumn{3}{c}{ Produtividade $\left(\mathrm{kg} \mathrm{ha}^{-1}\right)$} \\
\hline 18 de março de 2008 & 0,775 & $\mathrm{a}^{2}$ & $13,33^{3}$ & 1884,375 & $\mathrm{a}^{2}$ & $33,33^{3}$ \\
02 de abril de 2008 & 0,685 & $\mathrm{ab}$ & 6,67 & 634,375 & $\mathrm{bc}$ & 0,00 \\
18 de abril de 2008 & 0,733 & $\mathrm{ab}$ & 6,67 & 712,375 & $\mathrm{~b}$ & 6,67 \\
05 de maio de 2008 & 0,500 & $\mathrm{c}$ & 0,00 & 493,750 & $\mathrm{c}$ & 0,00 \\
23 de maio de 2008 & 0,600 & $\mathrm{bc}$ & 0,00 & 634,375 & $\mathrm{bc}$ & 0,00 \\
10 de junho de 2008 & 0,655 & $\mathrm{abc}$ & 0,00 & 718,750 & $\mathrm{~b}$ & 6,67 \\
DMS $^{1}$ & 0,163 & & & 211,892 & & \\
\hline
\end{tabular}

1 - Diferença mínima significativa para comparação de médias, pelo teste de Tukey a $5 \%$ de erro tipo I, ${ }^{2}$ - Médias seguidas pela mesma letra na coluna não diferem entre si pelo teste de Tukey a 5\%. ${ }^{3}$ - Resultados do teste de Fasoulas na comparação de médias, pelo teste de Tukey a 5\%, entre as diferentes datas de semeadura

a variedades de quinoa adaptadas a essas regiões, e com tratos culturais que possilitem atingir um melhor indice de produtividade. Uma vez que a produtividade da quinoa pode atingir $3.000 \mathrm{~kg} \mathrm{ha}^{-1}$ (SPEHAR; SANTOS, 2002), e neste trabalho foi obtido produtividade média de apenas $846 \mathrm{~kg} \mathrm{ha}^{-1}$. Evidenciando o quanto ainda pode ser otimizado o sistema de produção para quinoa na região de Campo Mourão.

\section{CONCLUSÕES}

1. A data de semeadura, dentro do período safrinha, teve influência do número de dias para a floração; número de dias para a maturação; altura das plantas na maturação e produtividade;

2. A maior altura de plantas juntamente à maior produtividade da quinoa foram obtidas em 18 de março.

\section{REFERÊNCIAS}

CARBONE-RISI, J. J. M. Adaptation of the Andean grain crop quinoa for cultivation in Britain. 1986. $123 \mathrm{f}$. Tese (Doutorado) - University of Cambridge, Cambridge, 1986.

COUTO, M. R. M. et al. Transformação de dados em experimentos com abobrinha italiana em ambiente protegido. Ciência Rural, v. 39, n. 06, p. 1701-1707, 2009.

CRUZ, C. D. Programa Genes: estatística experimental e matrizes. Viçosa: UFV. 2006. 285 p.

DAYNARD, T. B.; TANNER, J. W.; DUNCAN, W. G. Duration of the grain filling period and its relation to grain yield in corn, Zea mays L. Crop Science, v. 11, n. 01, p. 45-48, 1971.
FASOULAS, A. C. Rating cultivars and trials in applied plant breeding. Euphytica, v. 32, n. 03, p. 939-943, 1983.

PIMENTEL GOMES F. Curso de Estatística Experimental. São Paulo: Nobel, 1985. 467 p.

INOMOTO, M. M. et al. Reação de Dez Coberturas Vegetais a Pratylenchus brachyurus. Nematologia Brasileira, v. 30, n. 02, p. 151-157, 2007.

NELSON, D. C. Taxonomy and origins of Chenopodium quinoa and chenopodium nuttaliae. 1968. $101 \mathrm{f}$. Tese (Doutorado) - University of Indiana, Indiana, 1968.

OSÓRIO, E. A.; WENDT, W. Duração do período de formação do grão em trigo. Sciencia Agrícola, v. 52, n. 02, p. 395-398, 1995.

QUEIROZ, E. F. et al. Efeito de época de plantio sobre o rendimento da soja, na região norte do Paraná. Pesquisa Agropecuária Brasileira, v. 33, n. 09, p. 512-519, 1998.

ROCHA, J. E. da S. Seleção de genótipos de quinoa com características agronômicas e estabilidade de rendimento no Planalta Central. 2008. 115 f. Dissertação (Mestrado em Agronomia) - Universidade de Brasília, Brasília, 2008.

SANTOS, R. L. de B.; SPEHAR, C. R.; VIVALDI, L. Quinoa (Chenopodium quinoa) reaction to herbicide residue in a Brazilian Savannah soil. Pesquisa Agropecuária Brasileira, v. 38, n. 06, p. 771-776, 2003.

SOUZA, A. dos S. et al. Épocas de plantio e manejo da irrigação para a mamoneira. I - componentes de produção. Revista Ciência Agronômica, v. 38, n. 04, p. 414-421, 2007.

SPEHAR, C. R.; SANTOS, R. L. de B. Novas cultivares: Quinoa BRS Piabiru: Alternativa para diversificar os sistemas de produção de grãos. Pesquisa Agropecuária Brasileira, v. 37, n. 06, p. 889-893, 2002.

SPEHAR, C. R.; SANTOS, R. L. de B. Agronomic performance of quinoa selected in the Brazilian Savannah. Pesquisa Agropecuária Brasileira, v. 40, n. 06, p. 609-612, 2005. 
SPEHAR, C. R.; SANTOS, R. L. de B. Quinoa (Chenopodium quinoa Willd). Alternativa para a diversificação agrícola e alimentar. Planaltina: Embrapa Cerrados. 2003. 103 p.

SPEHAR, C. R.; SOUZA, P. I. de M. Adaptação da quinoa (Chenopodium quinoa Willd.) ao cultivo nos cerrados do planalto central. Pesquisa Agropecuária Brasileira, v. 28, n. 05, p. 635-639, 1993.

TAPIA, M. Cultivos andinos subexplotados y su aporte a la alimentación. Santiago: FAO, 1997. 217 p.
YANG, W. et al. Grain filling duration, a crucial determinant of genotypic variation of grain yield in field-grown tropical irrigated rice. Field Crops Research, v. 105, n. 03, p. 221-227, 2008.

ZUCHI, J. et al. Variações na qualidade e tamanho de sementes de mamona pela época de semeadura e ordem floral. Revista Ciência Agronômica, v. 41, n. 03, p. 403-408, 2010a.

ZUCHI, J. et al. Variações na qualidade e tamanho de sementes de mamona pela época de semeadura e ordem floral. Revista Ciência Agronômica, v. 41, n. 03, p. 380-386, 2010 b. 